\title{
Asthma knowledge, attitudes, and quality of life in adolescents
}

\author{
P G Gibson, R L Henry, G V Vimpani, J Halliday
}

\begin{abstract}
Adolescents with asthma, their peers, and their teachers were studied in order to establish the level of knowledge concerning asthma and its management, their attitudes towards asthma, and the degree quality of life impairment due to asthma. A community survey was conducted among year 8 high school students $(n=4161)$ and their teachers $(n=1104)$. There was a good response rate to the questionnaires from students $(93 \%)$ and teachers $(61 \%)$.

Twenty three per cent of students had asthma and this caused mild to moderate quality of life impairment, particularly with strenuous exercise. Asthma was provoked by passive smoke exposure in $30 \%$ of asthmatic students and up to $51 \%$ of students avoided situations because of asthma triggers.
\end{abstract}

Asthma knowledge was low in teachers (mean score 14.90 out of a possible 31 ), students without asthma $(11 \cdot 25)$ and students with asthma (14.50). Specific knowledge on the prevention and treatment of exercise induced asthma was poor. There was a moderate degree of tolerance towards asthma among all three groups. Most considered internal locus of control as important, although students without asthma also considered chance to be a determinant of outcomes for people with asthma.

Asthma is a common cause of quality of life impairment among year 8 high school students. Although specific knowledge on asthma is low, students and teachers hold favourable attitudes towards asthma. There are opportunities to intervene and improve asthma management among adolescents.

(Arch Dis Child 1995; 73: 321-326)

Keywords: asthma, quality of life.

Department of

Respiratory Medicine, John Hunter Hospital, and Discipline of Paediatrics, Faculty of Medicine and Health

Sciences, University of Newcastle, Australia

P G Gibson

R L Henry

G V Vimpani

J Halliday

Correspondence and reprin requests to: Dr P Gibson, Respiratory Medicine Unit, John Hunter Hospital, John Hunter Hospital, Locked Bag 1, Hunter

2310, Australia.

Accepted 16 May 1995 mortality among adolescents. It is one of the most common chronic illnesses in this age group $^{1-4}$ and a leading cause of school absence. ${ }^{5}$ Some of the problems of asthma in adolescence are common to other age groups, such as underrecognition, ${ }^{46}$ undertreatment, ${ }^{7}$ and non-compliance with therapeutic regimens. ${ }^{8}$ There are, however, specific issues relevant to asthma in adolescence. Adolescence is a period of transition from childhood to adulthood, where important psychological and physical changes occur. Peers assume greater influence, and there can be a denial of chronic illness and its treatment. ${ }^{9}$ These issues pose particular problems for the management of asthma during adolescence.

Asthma is now considered a chronic inflammatory condition of the airways and treatment approaches have changed. ${ }^{10}$ Many people with asthma require ongoing treatment to suppress inflammation, either on a daily basis, or for brief periods during asthma exacerbations. The ability of adolescents to comply with this management approach may be limited. They may reject the need for ongoing treatment, have difficulty in using existing health care facilities, ${ }^{11}$ or engage in risk taking behaviours such as smoking. ${ }^{12}$

Although there is general acceptance of the potential for difficulties with asthma management during adolescence, there is little specific information on why this occurs. Knowledge, attitudes, and beliefs are recognised as being major determinants of health behaviour, including compliance. ${ }^{13}$ Prior work has demonstrated a relationship between negative attitudes and morbidity in asthma. ${ }^{14}$ Since peers and teachers exert important influences during adolescence, ${ }^{15}$ the knowledge and attitudes of these groups could be expected to influence adolescents with asthma.

In this study, we sought to establish the level of knowledge concerning asthma and its management among adolescents with asthma, their peers, and their teachers. We also assessed the attitudes of these three groups towards asthma and examined the impact which asthma had on the quality of life of adolescents with asthma. The large sample size has allowed a comprehensive assessment of these issues in our community.

\section{Methods}

The study was conduced in 32 of the 33 departmental, Catholic, and independent secondary schools in the Greater Newcastle area of New South Wales, Australia. Students in year 8 $(n=4161)$ were requested to complete self administered asthma questionnaires during

Asthma is an important cause of morbidity and questionnaires to the school and teachers distributed the questionnaires to students who completed them during a 30-45 minute class. The questionnaires were collected by teachers, retrieved by the research assistant, checked against the class roll, and checked for completeness. Missing or incomplete questionnaires were redistributed on one other occasion. Students completed an asthma knowledge questionnaire, attitudes questionnaire, and asthma symptoms questionnaire. Students with current asthma also completed a quality of life questionnaire. 
Table 1 Characteristics of 958 students with current asthma

\begin{tabular}{ll}
\hline & No (\%) of students \\
\hline School absence due to asthma & $756(78)$ \\
Days missed & $5(1-99) \star$ \\
Asthma attacks at school & $416(43)$ \\
Current smoking & $206(22)$ \\
Medication (ever used) & $727(76)$ \\
Bronchodilator & $192(20)$ \\
Sodium cromoglycate & $401(42)$ \\
Inhaled corticosteroid & $90(9)$ \\
Ingested corticosteroid & \\
\hline${ }^{\star}$ Days missed is mean (range).
\end{tabular}

The asthma knowledge and attitudes questionnaires were also given to the school secretary for distribution to the teachers $(n=1815)$ at each of the participating secondary schools. Teachers were asked to complete the questionnaires in their own time and return them without personal identification to the school secretary. The research assistant then collected the questionnaires. Reminders were given to teachers to improve completion rates.

The study was approved by the ethics committee of the Hunter Area Health Service, the Hunter Region Department of Schools Education, and the Catholic Education Department.

\section{MEASUREMENTS}

\section{Asthma knowledge questionnaire}

The 31 item self administered Newcastle asthma knowledge questionnaire was used to assess knowledge of asthma, its symptoms, triggers, and treatments. ${ }^{16}$ Response options were presented as true/false/unsure ( 25 questions) or brief narratives (six questions). The questions were scored as previously and added to give a score out of 31 .

\section{Asthma attitudes questionnaire}

A 15 item self administered questionnaire assessed attitudes to asthma in four domains (appendix). The domains assessed were tolerance towards asthmatics (eight questions), and locus of control which was based on internal control (two questions), powerful others (three questions), and chance (two questions). Locus of control is a concept of representing the degree to which a person feels able to control events and circumstances in their life. ${ }^{17}$ The internal locus of control domain assesses the degree to which a person believes that their own decisions and actions influence their illness (asthma) and its effects. Students with strong internal locus of control are more likely to comply with a medical regimen. ${ }^{18}$ The 'powerful others' domain assesses the degree to which an individual believes that their scope for action concerning asthma and its management is under the control of important external people such as a doctor or teacher. People responding strongly in the chance domain considered that asthma and its effects were largely a result of chance. Responses were presented as six point Likert scales, ranging from 'strongly agree' (scored as 6), to 'strongly dis- agree' (scored as 1). Higher scores represented stronger attitudes in the domains assessed.

\section{Asthma symptoms questionnaire}

Subjects completed an 18 item questionnaire concerning their personal history of asthma symptoms, use of asthma treatments, and school absenteeism due to asthma. Based upon this questionnaire, current asthma was defined as the combination of a prior doctor's diagnosis of asthma together with either one or more attacks of asthma in the past 12 months or the use of asthma medication for asthma in the past 12 months.

\section{Asthma quality of life questionnaire}

Students with current asthma completed a 30 item self administered asthma quality of life questionnaire. ${ }^{19}$ Responses were presented as seven point Likert scales describing the degree of limitation experienced in the past two weeks and rated from none at all (scored as 7) to totally limited by asthma (scored as 1). The items were grouped into four domains as follows: asthma symptoms (12 questions), activities limited by asthma (nine questions), environmental triggers (four questions), and emotions (five questions). The results for each domain were summarised as a mean score, ranging from 1 to 7 . Overall quality of life was summarised as the mean score for the 30 items in the questionnaire. An additional item was included to assess the effect of personal smoking on asthma symptoms.

\section{ANALYSIS}

Categorical data were summarised as percentages and compared using the $\chi^{2}$ statistic. Data from the knowledge, attitudes, and quality of life questionnaires were compared using one way analysis of variance. Associations between variables were examined using Pearsons product moment correlation coefficient. Significance was accepted at the $\mathrm{p}<0.05$ level.

\section{Results}

Thirty two of the 33 schools agreed to participate in the study. Completed questionnaires were returned by $4161 / 4475(93 \%)$ of the year 8 students and $1104 / 1815(61 \%)$ of the teachers. The prevalence of current asthma was $23 \% \quad(n=958)$. Most $(756)$ of these children reported missing school due to asthma in the past year '(table 1). Ninety (9\%) students with asthma reported using prednisolone, indicating a severe asthma exacerbation in the past. About $22 \%$ of the asthmatics reported that they were current smokers with $86(42 \%)$ of them claiming that they experienced no asthma symptoms when smoking.

\section{QUALITY OF LIFE}

The quality of life questionnaire was completed by $796 / 958(83 \%)$ of the students with 
Table 2 Quality of life in students with asthma

\begin{tabular}{llll}
\hline Domain & Mean score (SD) & Activity & Students limited by asthma (\%) \\
\hline Activity limitation & $5 \cdot 2(1 \cdot 3)$ & Playing sport & 63 \\
Symptoms & $4 \cdot 9(1 \cdot 3)$ & Swimming & 45 \\
Emotions & $5 \cdot 2(1 \cdot 5)$ & Cycling & 55 \\
Environment & $4 \cdot 9(1 \cdot 3)$ & Running up hills & 78 \\
Overall & $5 \cdot 0(1 \cdot 5)$ & Surfing & $33^{\star}$
\end{tabular}

Students rated limitation due to asthma in the domains using a seven point Likert scale where 7 represented no limitation at all, and 1 represented totally limited by asthma. ${ }^{\star} \mathrm{p}<0.05$ surfing $v$ other activities.

asthma. The overall quality of life impairment due to asthma was in the mild to moderate range, with a mean (SD) value of $5 \cdot 0(1 \cdot 3)$ (table 2, fig 1). Severe limitation due to asthma was reported by $174 / 796(22 \%)$ (fig 1 ) of the asthmatics. In the symptoms domain, nocturnal asthma occurring at least most of the time in the past two weeks was reported by $167 / 751$ $(22 \%)$ of students. Environmental triggers such as dust, weather, air pollution, and strong smells were reported to have provoked recent asthma symptoms in about half of the students $(53 \%)$. Passive smoke exposure had provoked asthma in $36 \%$ of students. Between $37 \%$ and $51 \%$ of students reported avoiding situations because of potential exposure to these triggers, and $31.6 \%$ of the students had felt frustrated as a result of asthma, or concerned about having asthma in the past two weeks. A similar percentage $(42 \%)$ however, reported no emotional limitations due to asthma.

Asthma had limited the activities of $34.6 \%$ of students. Students identified specific activities which were limited by asthma from a list of 17 activities. The most frequently identified individualised activities that were impaired because of asthma were sleeping $(n=743)$, playing sports $(n=462)$, swimming $(n=274)$, bicycling $(n=237)$, going for a walk $(n=153)$, and surfing $(n=110)$ (table 2$)$. Students rated the severity of the limitation by asthma in five activities. Strenuous activities such as running upstairs or uphill and walking upstairs or uphill led to activity limitation by asthma in $78 \%$ and $79 \%$ of students respectively. Sporting activities in general caused limitation in $60 \%$ of the asthmatics. Although surfing is a strenuous physical activity, only $30 \%$ of the 110 asthmatics who had surfed in the past two weeks reported activity limitation by asthma while surfing $(\mathrm{p}<0.05$, table 2$)$.

\section{ASTHMA KNOWLEDGE}

Knowledge about asthma was, in general, low (table 3). Students with asthma had a mean asthma knowledge score of 14.5 , which is a level seen in a general community sample, and considerably less than informed parents who score at a level of $25 .{ }^{16}$ Students with asthma knew significantly more about asthma than students without asthma $(p<0.001)$. The asthma knowledge score among teachers was 14.9 , which is similar to that of students with asthma and significantly higher than students without asthma $(p<0.001)$. Female teachers $(n=589)$ had higher knowledge scores than male teachers $(15.80 v 13.88, \mathrm{p}<0.001)$. Higher knowledge scores were also seen in personal development/health/physical education teachers when compared with the remainder of the teaching body (16.91 $v 14.54$, $\mathrm{p}<0.001)$.

Important knowledge deficits were in the area of asthma recognition and the management of exercise induced asthma (table 3). A very low percentage of students and teachers could identify ways to prevent exercise induced asthma. Between $50 \%$ and $75 \%$ identified salbutamol as a treatment of acute asthma but few could name three asthma treatments which can be used during an attack of asthma. A disturbingly large percentage considered that asthmatic teenagers could become addicted to their drugs.

\section{ATTITUDES TOWARDS ASTHMA}

There was a moderately high degree of tolerance expressed towards a person with asthma (table 4, fig 2). This was greatest in students with asthma, and least in teachers $(p<0 \cdot 001)$. Forty six per cent of teachers agreed with the statement that 'students are embarrassed about using their inhalers in class' whereas $38 \%$ of students considered this to be the case $(p<0.05)$ (table 4$)$. The majority of students $(81 \%)$ and teachers $(70 \%)$ agreed with the statement that 'there would be fewer problems with asthma at school if students could carry their puffers around with them'.

The locus of control domains (fig 2) indicated that teachers and students with asthma supported control of the illness by the individual (internal control) as being more important than control by others (powerful others, for example, teacher, doctor) or by chance alone. Twenty five per cent of the students with asthma reported a high degree of internal control (score 6/6). Students without asthma saw chance as playing a greater role in asthma than did teachers or students with asthma $(p<0.001)$.

\section{ASSOCIATIONS}

Higher asthma knowledge was associated with positive attitudes and internal locus of control in asthma. The coefficient describing the relationship between asthma knowledge and

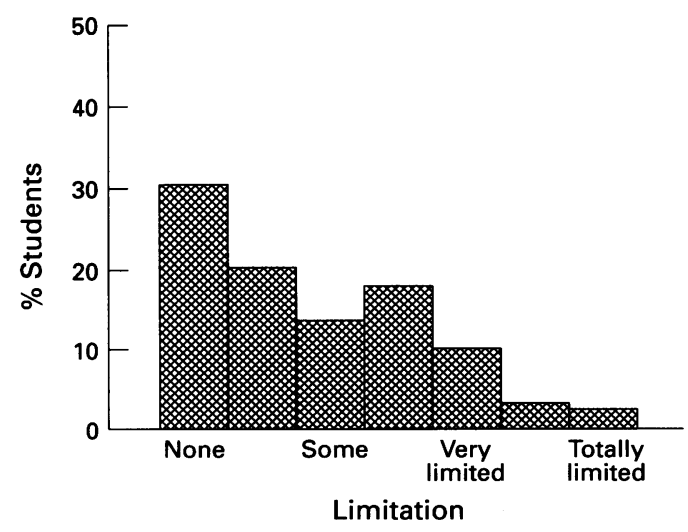

Figure 1 Frequency histogram of the degree of limitation caused by asthma in year 8 high school students with asthma. 
Table 3 Asthma knowledge in students and teachers

\begin{tabular}{|c|c|c|c|}
\hline & $\begin{array}{l}\text { Students with } \\
\text { asthma }(n=958)\end{array}$ & $\begin{array}{l}\text { Students without } \\
\text { asthma }(n=3203)\end{array}$ & $\begin{array}{l}\text { Teachers } \\
(n=1104)\end{array}$ \\
\hline $\begin{array}{l}\text { Mean (SD) asthma knowledge score } \\
\text { Specific knowledge items }\end{array}$ & $14 \cdot 5(5 \cdot 2)$ & $11 \cdot 25(4.55)^{\star}$ & $14 \cdot 90(5 \cdot 2)$ \\
\hline $\begin{array}{l}\text { What are the three main symptoms of } \\
\text { asthma? (\% correct) } \\
\text { Prevention of exercise induced asthma }\end{array}$ & $16 \cdot 9$ & $10 \cdot 1$ & $21 \cdot 7$ \\
\hline $\begin{array}{l}\text { (\% correct) } \\
\text { Asthma treatments which are useful }\end{array}$ & $1 \cdot 0$ & $0 \cdot 1$ & $5 \cdot 7$ \\
\hline $\begin{array}{l}\text { during an attack of asthma } \\
\beta_{2} \text { Agonist named (\%) } \\
\text { Three treatments named (\%) }\end{array}$ & $\begin{array}{l}71 \\
0 \cdot 3\end{array}$ & $\begin{array}{c}53 \cdot 3 \\
0\end{array}$ & $\begin{array}{r}76 \cdot 3 \\
3 \cdot 4\end{array}$ \\
\hline $\begin{array}{l}\text { Teenagers with asthma become addicted } \\
\text { to their drugs (\% correct) } \\
\text { Name two asthma treatments taken every } \\
\text { day to prevent asthma attacks from } \\
\text { occurring (\% correct) }\end{array}$ & $42 \cdot 2$ & $58 \cdot 6$ & $50 \cdot 9$ \\
\hline
\end{tabular}

${ }^{\star} \mathrm{p}<0.001$. Responses for specific knowledge items are the $\%$ of subjects in each group with a correct response for that item.

internal control was positive, indicating that students with higher internal control know more about asthma $(r=0.22, \mathrm{p}=0.0001)$. The relationships between asthma knowledge and the powerful others domain $(r=-0 \cdot 18$, $\mathrm{p}=0.0001)$ and between asthma knowledge and the chance domain $(r=-0 \cdot 16, p=0 \cdot 0001)$ had negative signs. This indicates that asthma knowledge was greater in those students who rated chance and powerful others as less important in attitude domains in asthma. There was a positive association between tolerance towards asthmatics and asthma knowledge $(r=0.21, p=0.0001)$ which is consistent with the concept that improved knowledge of a health problem promotes greater understanding and tolerance of individuals with that illness.

\section{Discussion}

Asthma was quite common in this group, and led to significant school absence and limitation in sporting activities. Asthma also caused mild to moderate impairment in quality of life. There was a low level of knowledge about asthma among teachers and adolescent students. Despite this, the groups appeared tolerant towards asthma during adolescence, and to the use of medications in the school environment.

The study targeted a restricted age group (13-14 years) but achieved a broad representation from this group with over $90 \%$ of students completing questionnaires. The results are therefore generalisable to this age group, within the sociodemographic confines of our population. The measurement tools included

Table 4 Specific attitudes towards asthma in students and teachers (\% agree)

\begin{tabular}{|c|c|c|c|}
\hline & Teachers & $\begin{array}{l}\text { Students with } \\
\text { asthma }\end{array}$ & $\begin{array}{l}\text { Students without } \\
\text { asthma }\end{array}$ \\
\hline $\begin{array}{l}\text { 'There would be fewer problems with asthma } \\
\text { at school if students could carry their } \\
\text { puffers with them' }\end{array}$ & $70 \cdot 3^{\star}$ & $82 \cdot 0$ & $79 \cdot 6$ \\
\hline $\begin{array}{l}\text { 'Someone with asthma should not use his/her } \\
\text { puffer in class' }\end{array}$ & $4 \cdot 0^{\star}$ & $8 \cdot 6$ & $13 \cdot 0$ \\
\hline $\begin{array}{l}\text { 'Students are embarrassed about using their } \\
\text { inhalers in class' }\end{array}$ & $45 \cdot 4^{\star}$ & 35.8 & $37 \cdot 3$ \\
\hline 'Students play on their asthma' & $30 \cdot 7^{\star}$ & $48 \cdot 2$ & $49 \cdot 1$ \\
\hline $\begin{array}{l}\text { 'Teachers are worried about taking someone } \\
\text { with asthma on a school camp or excursion' }\end{array}$ & $47 \cdot 1^{\star}$ & 53.9 & $56 \cdot 21$ \\
\hline $\begin{array}{l}\text { 'School teachers have a negative attitude to } \\
\text { students with asthma' }\end{array}$ & $6 \cdot 4^{\star}$ & $19 \cdot 8$ & $18 \cdot 4$ \\
\hline
\end{tabular}

asthma knowledge, attitudes, symptoms, and quality of life questionnaires. The Newcastle asthma knowledge questionnaire has been extensively validated and demonstrated to perform reliably and to discriminate among high and low knowledge groups. ${ }^{16}$ The quality of life questionnaire has undergone extensive evaluation and can be demonstrated to be a reliable instrument that is responsive to change and able to discriminate among asthmatics. ${ }^{19}$ The attitudes questionnaire contained items relating to locus of control and tolerance. The locus of control items were based on prior developmental work with an asthma specific locus of control questionnaire. ${ }^{7}$ The items for the tolerance domain were derived from responses of adolescent students with asthma during a focus group, from the comments of parents in an asthma support group on asthma management in schools and from the professional experience of the investigators. These items were screened for face validity by a multidisciplinary management team and each of the questionnaires underwent pilot testing in a neighbouring school before use in this study. The questionnaires were self administered in a school classroom setting to enhance the response rate.

The teacher questionnaires were also self administered, but were completed by teachers in their own time. This led to a reduced response rate from the teachers. The likely bias from this is that those teachers who were interested in the issue of asthma at school would have responded. If this were the case, our results for the teachers may actually be an overestimate of their knowledge and attitudes. This could be one explanation for the higher knowledge scores among teachers.

The level of knowledge concerning asthma was low. These results contrast with an earlier report of high knowledge among adolescent students. ${ }^{20}$ The knowledge questionnaire used in our study was more extensive. In addition to testing knowledge with regard to commonly held myths about asthma, the asthma knowledge questionnaire tested knowledge of treatments and management of exercise induced asthma.

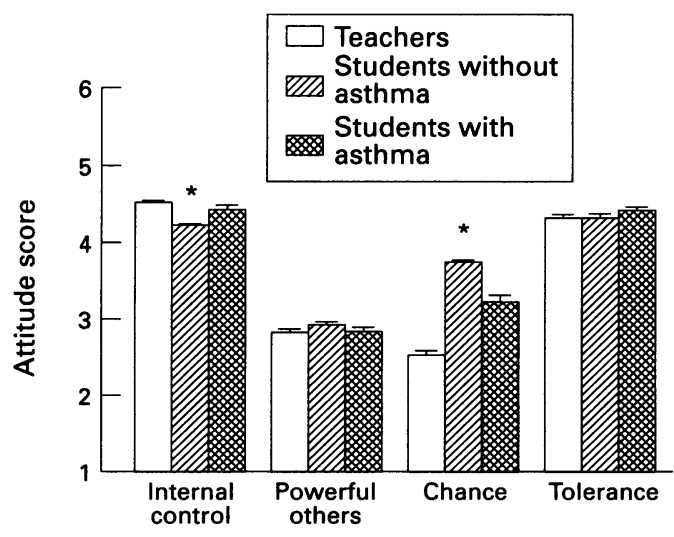

Figure 2 Attitudes towards asthma in teachers, students without asthma, and students with asthma scored from 1 (disagree) to 6 (strongly agree). The four attitude domains assessed were interval locus of control, powerful others locus of control, chance locus of control, and tolerance towards asthmatics; ${ }^{\star} p<0.01$. 
The prevalence of asthma was relatively high at $23 \%$. This is similar to the prevalence of asthma recorded in recent epidemiological surveys. ${ }^{2-4}$ Asthma led to school absence for a large number of the children and limited the activities of one third of the asthmatic children. This indicates that asthma was having a significant impact on the lives of the adolescent students in this community.

Almost half of the asthmatic children reported having attacks of asthma at school. The management of these episodes at the school is quite important. As there is a high likelihood that adolescents will have asthma attacks at school or during sport, there is a need for them to receive bronchodilator treatment promptly. This could be achieved by allowing students to carry their bronchodilators with them. The majority of students and teachers were supportive of this proposition (table 4). However, a recent survey of school principals did not identify uniform support for students carrying their medications. ${ }^{21}$ This issue should be addressed at each school and incorporated into the school policy for the management of asthma in schools. There are examples of national policies to assist in the formulation of local school policies. ${ }^{22}$

Even if students were allowed to carry their puffers, this may not be sufficient to ensure appropriate management of asthma attacks at school. The knowledge questionnaire identified significant defects in the understanding of how to manage exercise induced asthma among students and teachers. In agreement with this, many respondents (students and teachers) considered that teachers were worried about taking students with asthma on school camps or excursions. This indicates a need for specific training of teachers in the recognition and management of asthma attacks in students under their care. A programme to improve teacher knowledge and use of an asthma first aid kit has led to the satisfactory management of asthma attacks in primary schools. ${ }^{23}$

The knowledge deficit of students could be addressed by covering issues of asthma in the school. There are two programmes in high schools in New South Wales to address this. The high schools in this study have now entered a controlled trial of a three lesson asthma package delivered by teachers as part of the revised personal development/health/ physical education curriculum. ${ }^{24}$ A second intervention involves a peer led student asthma programme in high schools from a neighbouring region. These programmes will use similar evaluation strategies to allow comparison of the two interventions.

We found that the school environment was quite supportive of the issues regarding effective asthma management at school. Both teachers and peers of the students with asthma expressed tolerant attitudes towards asthma, and considered that dominant control of the illness should remain with the individual. These are positive findings which indicate that the school environment is receptive to intervention concerning asthma. The nonasthmatic peers should be included in these interventions. The peers are an important influence on the attitudes and behaviours of students with asthma, and the attitudes of peers towards asthma were clearly different from the students with asthma. The nonasthmatic peers tended to favour a greater role for external influences such as chance, teachers, and doctors in determining health outcomes in asthma. This differed from the students with asthma who expressed stronger attitudes towards internal control.

Self management of asthma is promoted as part of improved asthma care. Adolescence is a period of transition from parental control to self management in many life areas, including health behaviours. Self care has previously been linked to high internal locus of control. In this study, only $25 \%$ of the students with asthma reported high internal control. This may be due to the developmental stage of the students. The school environment during adolescence provides an opportunity to promote positive health care behaviours, and in particular, responsible self management.

Tobacco smoking is an important concern for respiratory health in adolescents, particularly those with asthma. Many adolescents begin smoking during this period and are vulnerable to its effects. Smoking is associated with undertreatment of asthma ${ }^{7}$ and passive smoking is a clinically significant risk factor for loss of lung function among young adults. ${ }^{25} 26$ Asthmatics are particularly susceptible to this effect, and can also develop acute airway narrowing after passive smoke exposure. ${ }^{27}$ Passive smoke exposure had an adverse effect on many of the asthmatics in this study. Over one third reported asthma symptoms provoked by recent passive smoke exposure and a similar proportion had to avoid situations because of potential tobacco smoke exposure. The prevalence of self reported cigarette smoking was alarmingly high for a group with asthma. It was similar to that reported among non-asthmatic adolescents $^{28}$ and is consistent with work suggesting that the presence of asthma does not necessarily deter students from smoking. ${ }^{29}$ There is a need to target smoking during adolescence. The findings of this study are that over half of the asthmatic smokers continue smoking despite experiencing asthma symptoms when smoking. This suggests a need to identify the attitudes and beliefs associated with smoking among adolescents, and to use this information to design effective smoking cessation messages.

In conclusion, this study has identified the quality of life impairment associated with asthma in adolescence and found a low level of knowledge about asthma and its management. The attitudes towards this illness among peers and teachers were generally positive, and indicate an opportunity to improve asthma management in the school environment.

This study was funded by the NH\&MRC. Gaye Sheather provided secretarial assistance. The authors acknowledge the assistance of Pauline Brown, Robyn Hankin, Patricia Kiehne, and Megan Valentine with data collection. Ian Shepherd and Wendy Arthur from the Department of Schools Education provided invaluable support during the planning of this project. We also thank the efforts of the year 8 students and their teachers who participated in this project. 
1 Newacheck PW, McManus MA, Fox HB. Prevalence and impact of chronic illness amongst adolescents. Am $\mathcal{F}$ Dis Child 1991; 145: 1367-73.

2 Robson B, Woodman K, Burgess C, et al. Prevalence of asthma symptoms among adolescents in the Wellington region, by area and ethnicity. $N Z M e d$ F 1993; 106: 239-41.

3 Pearce N, Weiland S, Kent V, et al. Self-reported prevalence of asthma symptoms in children in Australia, England, of asthma symptoms in children in Australia, England, Germany and New Zealand; an international comparison

Forero R, Bauman A, Young L, Larkin P. Asthma prevalence and management in Australian adolescents: results
lon from three community surveys. $\mathcal{F}$ Adolesc Health 1992; 13: from thre

5 Ford R, Dawson K, Cowie A. Asthma: does an accurate diagnosis influence attendance and performance? Aust NZ F Med 1988; 18: 134-6.

6 Bicho A, Damas L, De Lurdes Chierira M. Asthma in adolescence. Paedric Asthma, Allergy and Immunology 1992; 6: 197-203.

7 Gibson PG, Henry DA, Francis L, et al. Association between availability of non-prescription $\beta_{2}$ agonist inhalers and undertreatment of asthma. BMF 1993; 306: 1514-8.

8 Court JM. Adolescents and compliance. Current Therapy 1992; Oct: 55-9.

9 Hoffman D, Becker D, Gabriel H. The hospitalised adolescent: a guide to managing the ill and injured youth. New York: The Free Press, 1976 .

10 Warner J, Gotz M, Landau L, et al. Management of asthma: a consensus statement. Arch Dis Child 1989; 64: 1065-79.

11 Blum R. Youth's views of health and health services. Interdisciplinary adolescent health training workshop series. Compendium of materials. Rockville, Maryland: US Dept Health and Human Services, 1980.

12 Dielman TE, Campanelli PC, Shope JT, Butchart AT. Susceptibility to peer pressure, self-esteem and health locus of control as correlates of adolescent substance abuse. Health Educ Q 1987; 14: 207-21.

13 Becker MH, Maiman LA. Sociobehavioural determinants of compliance with health and medical care recommendations. Med Care 1985; 13: 10-24.

14 Charlton I, Charlton G, Broomfield J, Campbell M. An evaluation of a nurse-run asthma clinic in general practice using an attitudes and morbidity questionnaire. Fam Pract 1992; 9: 154-60.

15 Biddle BJ, Bank BJ, Martin MM. Parental and peer influence on adolescents. Social Forces 1980; 58: 1057-79.

16 Fitzclarence CAB, Henry RL. Validation of an asthma knowledge questionnaire. $\mathcal{F}$ Paediatr Child Health 1990; 26: 200-4

17 Wallston KA, Wallston BS, De Vellis R. Development of the multi-dimensional health locus of control (MHLC) scales. Health Education Monographs 1978; 6: 160-70.

18 Friedman IM, Litt IF. Adolescent's compliance with therapeutic regimens. Fournal of Adolescent Health Care 1987; 8: 52-67.

19 Juniper EF, Guyatt GH, Ferrie PJ, Griffiths LE. Measuring quality of life in asthma. Am Rev Respir Dis 1993; 147: 832-8.

20 Brook U, Kishon Y. Knowledge and attitude of healthy high school students toward bronchial asthma and asthmatic pupils. Chest 1993; 103: 455-7.

21 Henry RL, Pine JE, Gibson PG, Halliday JA, Vimpani GV. Inadequate asthma management policy in schools. Health Promotion fournal of Australia 1995; 5: 63-6.

22 Mellis CM, Bowes G, Henry RL, et al. A National policy on asthma management for schools. $\mathcal{f}$ Paediatr Child Health 1994; 30: 98-101.

23 Shah S, Gibson PG, Wachinger S. Recognition and crisis management of asthma in schools. F Paediatr Child Healt 1994; 30: 312-5.

24 Henry RL, Gibson PG, Hazell J, et al. Integrated health and education input in the development of an educationa package about asthma for schools. $\mathcal{F}$ Paediatr Child Health 1994; 30: 492-6.

25 Sherrill DL, Martinez FD, Lebowitz MD, et al. Longitudinal effects of passive smoking on pulmonary function in New Zealand children. Am Rev Resp Dis 1992; 145: 1136-41.

26 Jaakkola MS, Jaakkola JJ, Ernst P, Becklake MR. Ventilatory lung function in young cigarette smokers: study of susceptibility. Eur Respir f 1991; 4: 643-50.

27 Magnussen H, Lehnigk B, Oldigs M, Jorres R. Effects of acute passive smoking on exercise-induced bronchoacute passive smoking on exercise-induced bronchoconstrictio

28 Hill DR, White VM, Pain MD, et al. Tobacco and alcohol use among Australian secondary school children in 1987. Med f Aust 1990; 152: 124-30.

29 Brook U, Shiloh S. Attitudes of asthmatic and non asthmatic adolescents toward cigarettes and smoking. Clin Pediatr (Phila) 1993; 32: 642-6.

\section{Appendix}

ASTHMA ATTITUDES QUESTIONNAIRE

Below are some statements made by people about their asthma. For each statement please show how strongly you agree or disagree. Do this by placing in the box the number that best describes your feelings. Please answer all questions.

$\begin{array}{llllll}1 & 2 & 3 & \mathbf{4} & \mathbf{5} & \mathbf{6} \\ \begin{array}{l}\text { Strongly } \\ \text { agree }\end{array} & \text { Agree } & \begin{array}{l}\text { Tend to } \\ \text { agree }\end{array} & \begin{array}{l}\text { Tend to } \\ \text { disagree }\end{array} & \text { Disagree } & \begin{array}{l}\text { Strongly } \\ \text { disagree }\end{array}\end{array}$

1. If someone with asthma takes care of him/herself, he/she can avoid most asthma symptoms.

2. When someone has an attack of asthma symptoms at school, it is usually because he/she has been careless.

3. How soon someone recovers from an attack of asthma at school depends mainly on how well the teacher takes care of him/her.

4. When someone has an attack of asthma during sport, it is because the teacher hasn't checked up on whether the student has taken his/her medication.

5. If someone is going to have an attack of asthma, it will happen no matter what anyone does

6. How soon someone recovers from an attack of asthma symptoms is mostly a matter of luck.

7. Most people can control their asthma well without seeing a doctor regularly.

8. Someone with asthma should not use his/her puffer in class.

9. Students are embarrassed about using their inhalers in class.

10. Students without asthma have a negative attitude to students with asthma.

11. Students play on their asthma.

12. There would be few problems with asthma at school if students could carry their puffers around with them.

13. Teachers are worried about taking someone with asthma on a school camp or excursion.

14. Students with asthma are just as fit as students without asthma.

15. School teachers have a negative attitude to students with asthma. 